\title{
Myoglobinuric renal failure after prolonged sponsored activity
}

Using various parts of his body, a fourth Dan Master of Tae Kwon Do broke 2035 boards in four hours to raise money for the Live Aid appeal. Eight hours later he developed backache and acute renal failure. Examination showed extensive bruising of the right forearm. Myoglobin was detected in the plasma, and his urine, although dipstick positive for blood, contained no erythrocytes. Creatine phosphokinase activity was $1600 \mathrm{IU} / 1$. Spontaneous recovery occurred after four haemodialyses. Trauma and excessive physical activity $^{1}$ caused renal failure in this previously fit man. This case highlights the dangers of prolonged, severe physical exertion.-A R MORTON, S WALDEK, Hope Hospital, Salford M6 8HD.

1 Demos MA, Gitin EL, Kagen LJ. Exercise, myoglobinemia and acute exertional rhabdomyolysis. Arch Intern Med 1974;134(4): acute exert

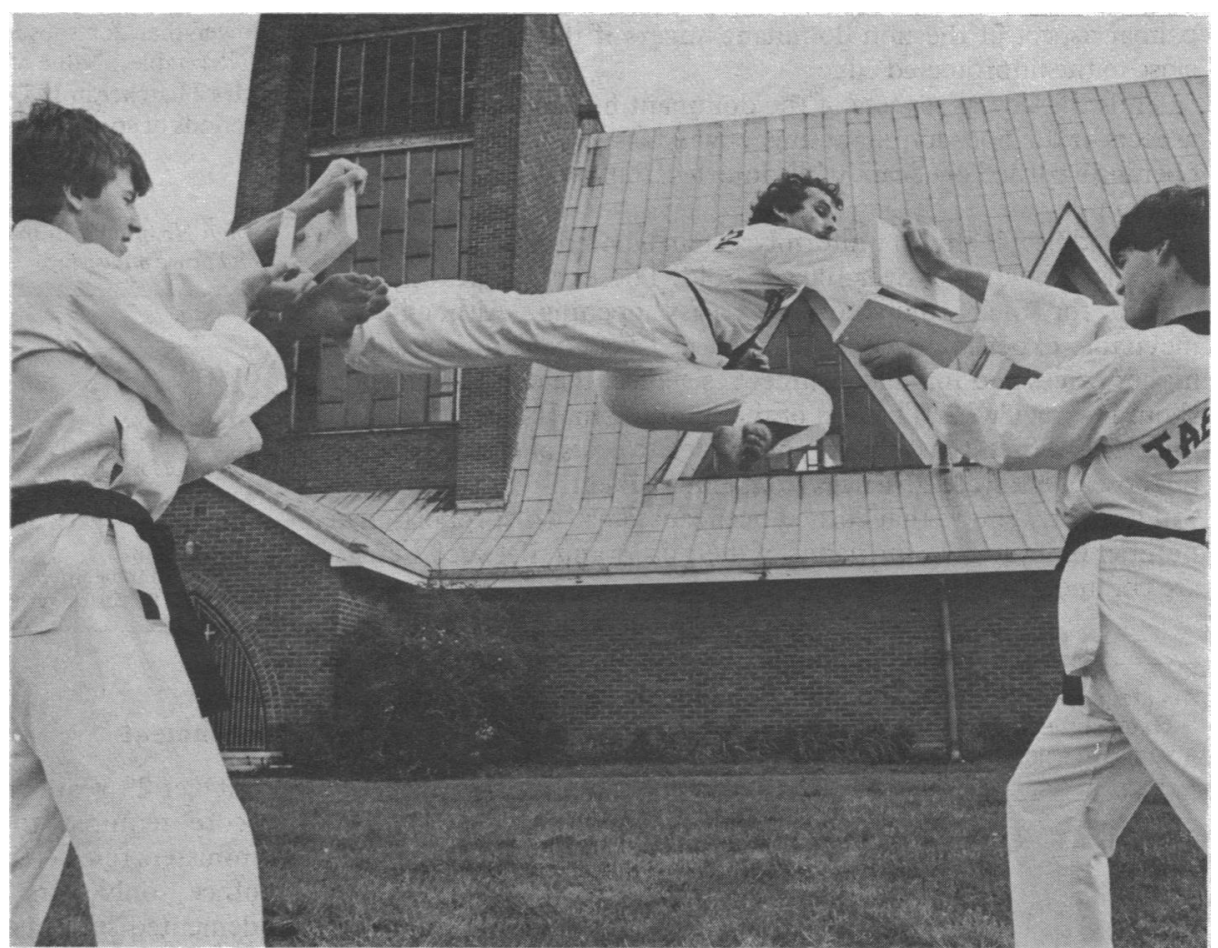

\section{Injuries from tin cans in patients presenting to an accident and emergency department}

Clinical impressions among the medical and nursing staff in this department were that a disproportionate number of injuries from tin cans were from corned beef cans. A prospective survey of all new patients with such injuries was therefore undertaken.

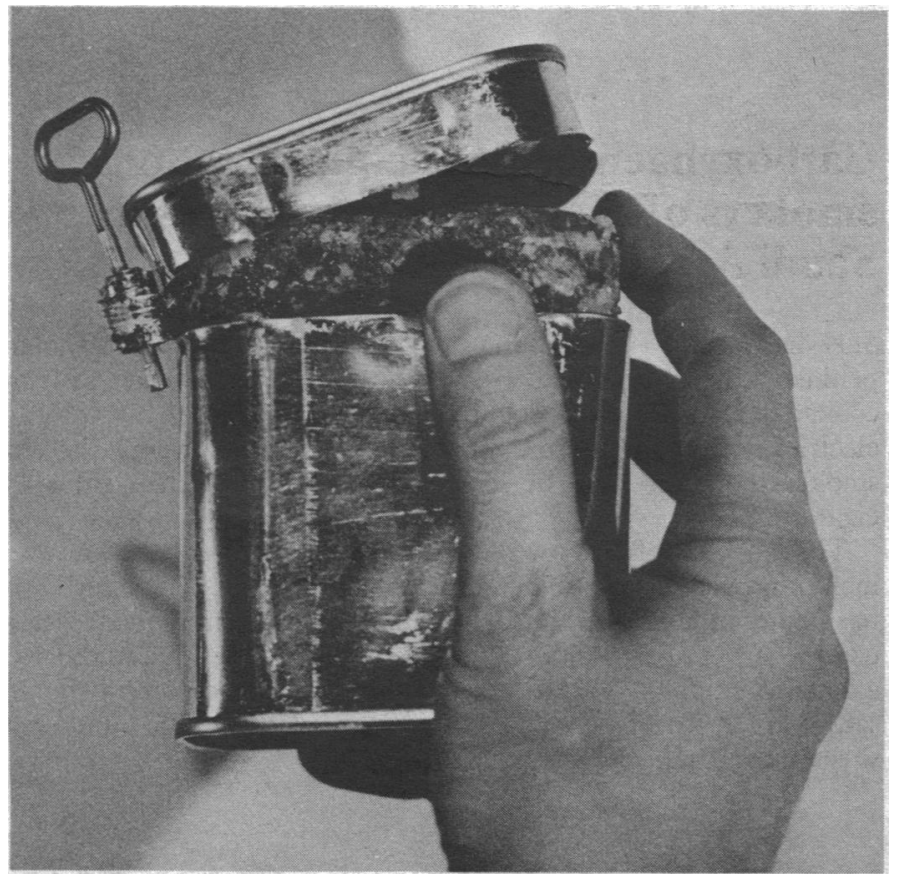

How injuries may happen: the partly opened lid may snap back into place, or fingers may be cut on the sharp edge of the tin.
Patients, methods, and results

All new patients presenting to the department with injuries from tin cans between 1 April and 30 June 1984 were surveyed using a simple questionnaire.

Of 15308 new patients who presented to the department during this period, $137(0.89 \%)$ had sustained injuries from tin cans. Corned beef cans were quoted in $102(74.5 \%)$ cases and other types of can in $35(25.5 \%), 34$ cases from cylindrical cans. Of the 102 patients with injuries from corned beef cans, 67 were female, and 35 male $(p<0 \cdot 05)$. Of the 35 others, 15 were female and 20 male (NS). The age range of the 137 injured patients was 7-82 (mean 39.6), and most (78) were aged 15-44. Differences in sex and age of the patients and the types of can were not significant.

Most injuries occurred between 1200 and 2000 , the peak time being between 1600 and 1800 ( $45 \%$ of all injuries), and $82.5 \%$ of all patients presented within two hours of injury. Time of injury and delay in presentation were irrespective of the type of can and the age and sex of the patient.

All patients required one or more of the following treatments: dressings ( $66 \%$ of all patients), steristrips $(48 \%)$, sutures $(42 \%)$, antibiotics $(16 \%)$, and antitetanus toxoid (15\%). No severe injuries were recorded. Of the 102 injuries from corned beef cans, 15 dominant hands were injured on the palmar and 30 on the dorsal aspects, and 41 non-dominant hands were injured on the palmar and 16 on the dorsal aspects. Of the 35 injuries from other cans, 13 were on the palmar and 14 on the dorsal aspects of the dominant hand, while three were on the palmar and five on the dorsal aspects of the non-dominant hand.

\section{Comment}

Of the 137 patients presenting with injuries from tin cans during the period of study, nearly three quarters had injuries from corned beef cans. After puncturing the top of the can the subject holds it in the non-dominant hand while the dominant hand unwinds a metal strip below the lip of the can on to the key provided. As the strip winds around the key the lid separates from the base and can be sprung back by the non-dominant hand. The can is inverted by the non-dominant hand and the meat released by shaking the can or prising it loose with a knife. If all this is done correctly the common mechanism of injury are: the partly opened lid snaps back into place, its sharp edge injuring the dorsal aspects of the operator's 
dominant fingers, or the sharp edge of the opened base injures the palmar aspect of the non-dominant fingers if the base is held too close to the unprotected edge.

Thus the dorsal aspects of the dominant fingers and the palmar aspects of the non-dominant fingers will be selectively at risk when opening a corned beef can, while injuries from other types of can are random.

Corned beef is almost uniformly sold in tapered, key opened cans, the design of which is over 100 years old. These cans were originally chosen for their robustness and easy opening. Although the inevitable expense of redesigning corned beef cans may result in higher prices and initial consumer resistance, the design of the can should be reviewed. The cost of the resulting morbidity from these injuries is difficult to quantify, but added to costs of treatment must be those of enforced absences from employment.

This study shows that corned beef cans cause a disproportionate number of injuries to the hands of their users and that such injuries are common.

Accident and Emergency Department, Queen Alexandra Hospital, Cosham, Hampshire

A W B CROCKETT, BM, DRCOG, senior house officer

\section{Dementia and Mrs Thatcher}

We have had the impression that psychogeriatric patients seem more prone to recall Margaret Thatcher correctly than has been the case for other prime ministers. We tested the hypothesis that in demented patients Mrs Thatcher would be recalled more easily than other prime ministers who had served a similar period in office and that she is now recalled more easily than the Queen.

\section{Subjects and methods}

A retrospective study was performed on consecutive admissions to the psychogeriatric wards of the Bethlem and Maudsley hospitals for the years 1961-2, 1968-9, and 1983-4. These correspond with the fourth and fifth years of the terms of office of $\mathrm{Mr}$ MacMillan, $\mathrm{Mr}$ Wilson, and Mrs Thatcher, respectively. Eligible patients were aged 65 and over and had a main diagnosis of organic dementia on admission.

The total score on either the Felix post questionnaire (for some patients in years 1983-4, scored out of 20) or the Gresham ward questionnaire (for all patients in the years 1961-2 and 1968-9 and for some in 1983-4, scored out of 43) was recorded. The responses to the question concerning the identity of the reigning monarch and current prime minister were recorded separately.

\section{Results}

Those subjects too severely demented to register any score on either questionnaire - that is, $0 / 20$ or $0 / 43$ - or to allow the administration of the questionnaire were excluded. For the purposes of analysis this gave 43 patients from 1961 to 1962, 27 from 1968 to 1969, and 44 from 1983 to 1984. The mean age, cognitive score, and length of stay were compared with $t$ tests and were not significantly different between groups. Two by two $\chi^{2}$ tests showed no significant differences in the male to female ratios between years.

The average cognitive score of those patients who correctly recalled Queen Elizabeth II as the monarch were compared with $t$ tests and were not significantly different between groups.

Two by two $\chi^{2}$ tests compared correct and incorrect recall of the monarch and prime minister within each group (table). In 1961-2 the Queen was recalled more often than $\mathrm{Mr}$ Macmillan $\left(\chi^{2}=6.70, \mathrm{df}=1, \mathrm{p}<0.01\right)$ and a similar trend was evident for Mr Wilson in $1968-9\left(\chi^{2}=2 \cdot 7, \mathrm{df}=1, \mathrm{p} \approx 0 \cdot 1\right)$. In 1983-4 Mrs Thatcher was recalled more often than the Queen $\left(\chi^{2}=6.56\right.$, $\mathrm{df}=1, \mathrm{p}<0 \cdot 02)$. Mrs Thatcher was recalled more often than $\mathrm{Mr}$ Macmillan $\left(\chi^{2}=6.20, \mathrm{df}=1, \mathrm{p}<0.02\right)$ and, although remembered more often than $\mathrm{Mr}$ Wilson $\left(\chi^{2}=1 \cdot 89, \mathrm{df}=1\right)$, the result was not significant. No difference was observed in ease of recall between Mr Wilson and Mr Macmillan $\left(\chi^{2}=0 \cdot 65\right.$, $\mathrm{df}=1, \mathrm{NS})$.
From $t$ tests the mean cognitive score for those recalling Mrs Thatcher was lower than for those who recalled $\mathrm{Mr}$ Wilson $(\mathrm{p}<0.05)$ or $\mathrm{Mr}$ Macmillan (NS) (table). None of these achieved significance, but the score for recall of Mrs Thatcher in 1983-4 was lower than that for the Queen in any of the three periods of study.

Total No of patients in each study group correctly and incorrectly recalling the Queen and prime minister

\begin{tabular}{|c|c|c|c|}
\hline & $1961-2$ & $1968-9$ & $1983-4$ \\
\hline \multicolumn{4}{|l|}{ Queen: } \\
\hline Know & 27 & 18 & 15 \\
\hline Don't know & 16 & 9 & 29 \\
\hline \multicolumn{4}{|l|}{ Mean (SD) cognitive } \\
\hline \multicolumn{4}{|l|}{ Prime minister: } \\
\hline Know & 15 & 12 & 27 \\
\hline Don't know & 28 & 15 & 17 \\
\hline \multicolumn{4}{|l|}{ Mean (SD) cognitive } \\
\hline score for correct responses & $49 \cdot 9(18 \cdot 3)$ & $54 \cdot 8(25 \cdot 6)$ & $41 \cdot 0(22 \cdot 1)$ \\
\hline
\end{tabular}

\section{Comment}

Over 23 years demented patients did not differ in the cognitive score required to recall Queen Elizabeth II. Of three prime ministers re-elected for second terms and spending over five years in office, only Mrs Thatcher entered into the consciousness of demented subjects to an extent that made her easier to recall than the Queen. We have also presented evidence indicating that the recall of Mrs Thatcher is possible at cognitive levels that hitherto precluded memory for the Prime Minister.

We can only say that somehow Mrs Thatcher has given an item of knowledge to demented patients that they would otherwise have lacked: she reaches those parts of the brain other prime ministers could not reach.

The Maudsley Hospital, Denmark Hill, London SE5

IAN J DEARY, MB, CHB, senior house officer

SIMON WESSELY, MA, MRCP, registrar

MICHAEL FARRELL, MRCP, registrar

Correspondence to: Dr Ian J Deary, Department of Psychology, University of Edinburgh, Edinburgh EH8 9JZ.

\section{Carboxyhaemoglobin concentrations in smokers of sheesha and cigarettes in Saudi Arabia}

Sheesha (figure) is a smoking device widely used in the Arabian peninsula to smoke jurak, which is a mixture of tobacco and fruit cooked to produce a dark coloured paste. Jurak may be burnt by an electrical device or more commonly by charcoal. Many sheesha smokers consider it to be less harmful to health than smoking cigarettes.

The adverse effects of smoking cigarettes are well known, ${ }^{1}$ including those attributed to carbon monoxide. ${ }^{1-2}$ The carboxyhaemoglobin concentration in the blood has been shown to be a useful marker of absorption of tobacco smoke. ${ }^{3}$ We have conducted a detailed study on the estimated amounts of carboxyhaemoglobin saturation in sheesha or cigarette smokers relative to the number of sheeshas or cigarettes smoked a day.

\section{Subjects, methods, and results}

We studied 1832 healthy male volunteers from Saudi Arabia aged 16-73 years. The medical history and usual smoking habits of each participant 